\title{
MicroRNA-33a and MiR-34a as a Molecular Targets for Pomegranate Peel Extract During Treatment of Non-Alcoholic Fatty Liver Disease in Rats.
}

\author{
Abada E. khadr ${ }^{*}$,Maher A. Kamel ${ }^{2}$, Nasser H. Abbas ${ }^{1}$ and Mohamed E. Ebeid ${ }^{1}$, Weal \\ S. Darwish ${ }^{1}$. \\ ${ }^{1}$ Molecular Biology and Biochemistry department, Genetic Engineering and \\ Biotechnology Research Institute (GEBRI), University of Sadat City, Egypt.2- \\ ${ }^{2}$ Medical Research Institute, University of Alexandria, Egypt. \\ *Corresponding author: Email:d.abada_khadr@yahoo.com
}

\begin{abstract}
Non-alcoholic fatty liver disease (NAFLD), hepatic manifestation of metabolic syndrome, has been considered the most common liver disease nowadays. The aim of this study is to evaluate the potential therapeutic effect of pomegranate peel extract on the experimental rat model of nonalcoholic fatty liver diseases (NAFLD) and to explore the role of mir-33a and mir-34a as the molecular targets for these therapeutic effects.Fifty male albino Wistarrats were used in the present study. The NAFLD was induces in rats using high fat diet (HFD). The pomegranate peel extract (PPE) was used in different doses $(50,100$ and 150) for 30 days.The present study documents the ameliorating effects of PPE on hyperglycemia, insulin resistance, lipid profile and liver functions in NAFL rats in a dose-dependent manner compared to untreated rats. The ameliorating effects on the metabolic parameter are associated with significant correction in the hepatic expression of MiR-33a and MiR-34ain a dose-dependent manner. From the present study we can concluded that the PPE have efficient anti-steatotic effect which may be mediated through modulation of MiR-33a and MiR34.
\end{abstract}

Key words: NAFL, MiR-33a, MiR-34a, PPE.

\section{Introduction}

Non-alcoholic fatty liver disease (NAFLD) is the most common cause of chronic liver disease, affecting approximately $30 \%$ of global populations. Fatty liver has been documented in up to 10 to 15 percent of normal individuals and 70 to 80 percent of obese individuals (Younossiet al., 2002). Fatty liver includes a wide spectrum of histological alterations ranging from simple steatosis to nonalcoholic steatohepatitis (NASH), characterized by inflammation and fibrosis (Paiset al., 2013). NAFLD is regarded as the liver manifestation of the metabolic syndrome, as it is strongly associated with obesity, insulin resistance, hypertension, and dyslipidemia (Souza and Diniz, 2012), conditions associated with high cardiovascular risk. The development of NAFLD and its progression are multifactorial processes due to the involvement of many different pathways remain unclear and require further investigations (Pastoriet al., 2015). 
Mir-33a is one of the most important microRNAs in liver, miR-33 contributes to the modulation of fatty acid metabolism and insulin signaling pathways, as well as the dysregulation of cholesterol synthesis and high-density lipoprotein (HDL) levels (Zhen and Cheng, 2016). miR-33 reduced the expression of genes associated with fatty acid synthesis (SREBP, fatty acid synthase, ATP citrate lyase, and acetylCoA carboxylase $\alpha$ ) and concomitantly elevated plasma HDL levels(Rayneret al., 2011).

MicroRNA-34a is a family of microRNA, it found in several animal species, including humans. MicroRNA-34a was found to be up-regulated in patients with nonalcoholic fatty liver disease and hepatitis $\mathrm{C}$ virus infection (Cermelliet al., 2011) and down-regulated in multiple tumors including hepatocellular carcinoma (Budhuet al., 2008). MiR-34a plays an important role in lipid metabolism (van der Meer et al., 2012).It is highly expressed in patients with non-alcoholic fatty liver disease, non-alcoholic steatohepatitis (NASH) (Cheung et al., 2008) and type 2 diabetes (Kong et al.,2011).

The Pomegranate fruit could be considered a functional food because it has valuable compounds in different parts of the fruit that display functional and medicinal effects. These compounds can act as antioxidant (Cam et al., 2009), as antitumor (Hamad and Al-Momene, 2009) as antihepatotoxic agents (Celiket al., 2009), and improve cardiovascular health (Davidson et al., 2009). They have been reported to have antidiabetic properties and help to prevent Alzheimer's disease (Singh et al., 2008).Pomegranate peel extract (PPE) also have an effect on lipid metabolism, (Hossin, 2009).

The present study was designated to investigate the therapeutic effects of pomegranate peel extract (PPE) on HFDinduced NAFLD in rats at different levels; hepatic lipid content, liver function test, glucose homeostasis, lipid abnormalities and hepatic expression of microRNAs (miR-33a and miR-34a).

\section{Material and Method}

\subsection{Animals and diet}

In the present study, we used 50 local Wistar male rats weighing approximately (150-170 grams) and aged 2-3 months, obtained from animal house of Medical Research Institute. Rats were divided into two groups: control group (group I; $n=10$ ) and non-alcoholic fatty liver (NAFL) group, (group II; $n=40$ ). The control group was fed a standard diet. The NAFL group was fed a high fat diet (HFD) for 14 weeks. The model was based on the model reported by Fiorese, et al. 2008 (Sene-Fioreseet al., 2008). The HFD consisted of commercial rat chow plus peanuts, milk chocolate, and sweet biscuit in a proportion of 3:2:2:1. All components of the high-fat diet were ground and blended.

\subsection{Pomegranate Peel Extract:}

For preparation of pomegranate peel extract, a peel was removed and dried. The dried plant materials were powdered 
using a grinder. About $100 \mathrm{mg}$ of dried, ground plant materials was soaked in methanol (1 L) for 24 hours at room temperature, followed by filtration through Whatman filter paper. The filtrate was centrifuged at $8000 \mathrm{rpm}$ for $15 \mathrm{~min}$, the clear supernatant will be collected, and then the methanol was evaporated in Arotary evaporator at $45^{\circ} \mathrm{C}$ under reduced pressure (Laporniket al., 2005).

\subsection{Experimental procedures}

After establishing NASH the rats were divided into 2 groups; NAFLD group: 10 NAFLD rats without treatment and NAFLD treated with pomegranate peel extract (30 rats): after establishing NAFLD, the rats were treated daily with pomegranate peel extract using different doses $(50,100$ and $150 \mathrm{mg} / \mathrm{kg}$ body weight) were administered to rats orally for 30 days by using 10 rats for each dose (Svegliati-Baroniet al., 2006). At the end of treatment period, overnight fasting rats were weighed and sacrificed by cervical dislocation and blood samples were collected to obtain serum for assessment of glucose, insulin, bilirubin, lipid profile, alanine aminotransferase (ALT), asparatate aminotransferase (AST) and gamma-glutamyltransferase (GGT).

The liver of animals were quickly removed and washed with ice-cold saline. Livers were then divided into small parts for total RNA extraction.

\subsection{Methods:}

\subsubsection{Serum parameters:}

The AST,ALT and GGT were assessed using Biosystem kinetic kits (Biosystem,
Spain) (Panteghini and Bais, 2008), Total Bilirubin was determined using BioMed colorimetric kit (BioMed, Germany)(Burtiset al., 2006), insulin was determined by ELISA kit (Biospes, China) (Weyeret al., 2000) and fasting serum glucose was assessed using SPINREACT colormetric Kit (SPINREACT, SPAIN) (Sacks, 2008). The homeostasis model assessment index for insulin resistance (HOMA-IR) was determined using the following formula: HOMA-IR $=$ [fasting glucose $(\mathrm{mg} / \mathrm{dl}) \times$ fasting insulin $(\mu \mathrm{U} / \mathrm{ml})] /(22.5 \times 18)$ (Fenget al., 2017).

For lipid profile, the serum levels of triglycerides (TGs) and total cholesterol (TC) were determined using Boehringer Mannheim colorimetric kits (Mannheim, Germany), while HDL-C was determined according to the method described by Lopes-Virella et al (Rifai and Warnick, 2008).; one aliquot of the serum was mixed with the precipitating reagent phosphotungstic acid and magnesium chloride then the cholesterol content was evaluated in the clear supernatant using the Boehringer Mannheim kit (Mannheim, Germany). Finally, LDL-C was calculated according to the Friedewald equation: (Friedewaldet al., 1972).

$$
\begin{aligned}
& \text { LDL-C }=\text { total cholesterol - } \\
& (\text { HDL-C })-(T G / 5)
\end{aligned}
$$

\subsubsection{Liver parameters:}

Immediately after blood collection, livers were excised and divided into aliquots; one aliquot was used for determination of hepatic triglycerides and cholesterol 
contents and $50 \mathrm{mg}$ was used for total RNA extraction using miRNeasy kit (Qiagen, Germany) according to the manufacturer's instructions.

\subsubsection{Assessment of tissue lipid contents}

Hepatic lipids were extracted according to the method modified by Folich method (Folichet al., 1975). Where the chloroform layer, containing all lipids, was utilized to assay TGs and TC, as mentioned before.

\subsubsection{Reverse transcription of total RNA}

Reverse transcription was done using miScript II RT Kit (Qiagen,Germany) according to the manufacturer instructions. The miScript II RT Kit is used to perform a one-step, single-tube reverse transcription reaction. miScriptHiFlex Buffer was used to promote conversion of all RNA species (mature miRNA, precursor miRNA, noncoding RNA, and mRNA) into cDNA. This enables flexibility to study miRNA biogenesis and mRNA regulation in a single cDNA sample.

\subsection{Assessment of hepatic expression of microsRNAs:}

The obtained cDNAs were used for realtime PCR quantification of mature miRNAs (mir-34a and mir-33a) using Primer Assays (forward primers) and the miScriptSYBR Green PCR Kit, which contains the miScript Universal Primer (reverse primer) and QuantiTectSYBR Green PCR Master Mix
(Qiagen,Germany). The kit was used with miScriptPCR Control

U6(Qiagen,Germany). Data were collected using Rotor-Gene Q-Pure Detection version 2.1.0 (build 9) (Qiagen, USA). The relative expression of miRNAs was quantified relative to the expression of the reference gene (U6) in the same sample by calculating and normalizing the threshold cycles $(\mathrm{Ct})$ values of target miRNAs to that of U6 using $\Delta \Delta \mathrm{Ct}$ method.

3. Statistical analysis of the data (Kotzet al., 2006).

Data were fed to the computer and analyzed using IBM SPSS software package version 20.0. (Armonk, NY: IBM Corp) (Kirkpatrick and Feeney, 2013). The Kolmogorov-Smirnov test was used to verify the normality of distribution Quantitative data was described using mean and standard deviation. Significance of the obtained results was judged at the $5 \%$ level.

\section{Results:}

\subsection{Liver parameters}

The results show the untreated NAFL rats showed significantly higher serum activities of ALT, AST and GGT by about $95.2,53.1$ and $292.6 \%$ respectively compared to control rats. Also, the results showed an elevation in serum bilirubin by about $253.9 \%$. The rats which treated with Pomegranate peel extract showed significantly lower level of liver enzymes (ALT, AST and GGT) and bilirubin compared to untreated rats in a dosedependent manner, Table (1). 
Table 1.Liver enzymes and bilirubin

\begin{tabular}{|c|c|c|c|c|c|}
\hline & \multirow{2}{*}{$\begin{array}{l}\text { Control } \\
(n=10)\end{array}$} & \multirow{2}{*}{$\begin{array}{c}\text { NAFAL rats } \\
\text { Untreated } \\
(\mathbf{n}=\mathbf{1 0})\end{array}$} & \multicolumn{3}{|c|}{ NAFAL rats treated } \\
\hline & & & $\begin{array}{c}50 \mathrm{mg} / \mathrm{Kg} \\
(\mathrm{n}=10)\end{array}$ & $\begin{array}{c}100 \mathrm{mg} / \mathrm{Kg} \\
(\mathrm{n}=10)\end{array}$ & $\begin{array}{c}150 \mathrm{mg} / \mathrm{Kg} \\
(\mathrm{n}=10)\end{array}$ \\
\hline ALT & $33.0 \pm 5.03$ & $64.4^{\mathrm{a}} \pm 15.46$ & $40.30^{\mathrm{b}} \pm 6.62$ & $36.90^{\mathrm{b}} \pm 6.64$ & $34.40^{\mathrm{b}} \pm 9.57$ \\
\hline$\%$ of change 1 & & $\uparrow 95.2$ & $\uparrow 22.1$ & $\uparrow 11.8$ & $\uparrow 4.2$ \\
\hline$\%$ of change 2 & & & $\downarrow 37.4$ & $\downarrow 42.7$ & $\downarrow 46.6$ \\
\hline AST & $110.20 \pm 22.26$ & $168.70^{\mathrm{a}} \pm 22.10$ & $147.10^{\mathrm{a}} \pm 12.47$ & $130.50^{\mathrm{b}} \pm 21.42$ & $115.30^{\mathrm{bc}} \pm 14.26$ \\
\hline$\%$ of change 1 & & $\uparrow 53.1$ & $\uparrow 33.5$ & $\uparrow 18.4$ & $\uparrow 4.6$ \\
\hline$\%$ of change 2 & & & $\downarrow 12.8$ & $\downarrow 22.6$ & $\downarrow 31.7$ \\
\hline Total Bilirubin & $0.36 \pm 0.05$ & $1.27^{\mathrm{a}} \pm 0.15$ & $0.59^{\mathrm{ab}} \pm 0.27$ & $0.45^{\mathrm{b}} \pm 0.14$ & $0.33^{\mathrm{bc}} \pm 0.13$ \\
\hline$\%$ of change 1 & & $\uparrow 253.9$ & $\uparrow 63.9$ & $\uparrow 25.0$ & $\downarrow 8.3$ \\
\hline$\%$ of change 2 & & & $\downarrow 53.5$ & $\downarrow 64.6$ & $\downarrow 74.0$ \\
\hline GGT & $12.10 \pm 2.65$ & $47.50^{\mathrm{a}} \pm 5.93$ & $25.06^{\mathrm{ab}} \pm 5.32$ & $17.15^{\mathrm{abc}} \pm 2.19$ & $14.78^{\mathrm{bc}} \pm 1.64$ \\
\hline$\%$ of change 1 & & $\uparrow 292.6$ & $\uparrow 107.1$ & $\uparrow 41.7$ & $\uparrow 22.1$ \\
\hline$\%$ of change 2 & & & $\downarrow 47.2$ & $\downarrow 63.9$ & $\downarrow 68.9$ \\
\hline
\end{tabular}

\section{Data was expressed as mean $\pm \mathrm{SD}$.}

a: significant with Control group at $\mathrm{p} \leq 0.05$

b: significant with Untreated group at $\mathrm{p} \leq 0.05$

c: significant with $\mathbf{5 0} \mathbf{~ m g / K g}$ group at $\mathrm{p} \leq 0.05$

$\%$ of change 1: from Control group

$\%$ of change 2: from Untreated group

*: Statistically significant

\subsection{Glucose homeostasis parameters:}

The results indicated that the untreated NAFL rats showed significantly higher serum levels of fasting blood glucose and insulin compared to control rats by about $74.2 \%$ and $118.8 \%$, respectively. HOMAIRI also increased by 3.7- folds compared to control rats. The NAFL rats treated withPomegranate peel extract showed significantly lower values of fasting blood glucose, insulin and HOMA-IRI compared to untreated in a dose dependent manner, Table (2).

Table 2. Glucose homeostasis parameters 


\begin{tabular}{|c|c|c|c|c|c|}
\hline & \multirow{2}{*}{$\begin{array}{l}\text { Control } \\
(n=10)\end{array}$} & \multirow{2}{*}{$\begin{array}{l}\text { NAFAL rats } \\
\text { Untreated } \\
(n=10)\end{array}$} & \multicolumn{3}{|c|}{ NAFAL rats treated } \\
\hline & & & $\begin{array}{c}50 \mathrm{mg} / \mathrm{Kg} \\
(\mathrm{n}=10)\end{array}$ & $\begin{array}{c}100 \mathrm{mg} / \mathrm{Kg} \\
(\mathrm{n}=10)\end{array}$ & $\begin{array}{c}150 \mathrm{mg} / \mathrm{Kg} \\
(\mathrm{n}=10)\end{array}$ \\
\hline $\begin{array}{l}\text { Insulin } \\
(\mathrm{uIU} / \mathrm{ml})\end{array}$ & $3.82 \pm 0.85$ & $8.36^{\mathrm{a}} \pm 0.94$ & $4.99^{\mathrm{ab}} \pm 0.78$ & $3.90^{b c} \pm 0.63$ & $3.58^{b c} \pm 0.54$ \\
\hline$\%$ of change 1 & & $\uparrow 118.8$ & $\uparrow 30.6$ & $\uparrow 2.1$ & $\downarrow 6.3$ \\
\hline$\%$ of change 2 & & & $\downarrow 40.3$ & $\downarrow 53.3$ & $\downarrow 57.2$ \\
\hline FBS & $99.20 \pm 10.25$ & $172.8^{\mathrm{a}} \pm 44.3$ & $144.0^{\mathrm{a}} \pm 17.33$ & $126.6^{b} \pm 23.85$ & $119.2^{b} \pm 23.44$ \\
\hline$\%$ of change 1 & & $\uparrow 74.2$ & $\uparrow 45.2$ & $\uparrow 27.6$ & $\uparrow 20.2$ \\
\hline$\%$ of change 2 & & & $\downarrow 16.7$ & $\downarrow 26.7$ & $\downarrow 31.0$ \\
\hline HOMA & $0.95 \pm 0.27$ & $3.55^{\mathrm{a}} \pm 0.93$ & $1.78^{\mathrm{ab}} \pm 0.38$ & $1.23^{\mathrm{b}} \pm 0.33$ & $1.05^{\mathrm{bc}} \pm 0.24$ \\
\hline$\%$ of change 1 & & $\uparrow 274.1$ & $\uparrow 87.8$ & $\uparrow 29.7$ & $\uparrow 10.8$ \\
\hline$\%$ of change 2 & & & $\downarrow 49.9$ & $\downarrow 65.4$ & $\downarrow 70.4$ \\
\hline
\end{tabular}

Data was expressed as mean \pm SD.

a: significant with Control group at $\mathrm{p} \leq 0.05$

b: significant with Untreated group at $\mathrm{p} \leq 0.05$

c: significant with $\mathbf{5 0} \mathbf{~ m g / K g}$ treatedgroup at $\mathrm{p} \leq 0.05$

$\%$ of change 1: from Control group

$\%$ of change 2: from Untreated group

\subsection{Lipid parameters:}

\subsubsection{Serum lipid profile:}

The results indicated that the untreated NAFL rats showed significant higher levels of TG, TC and LDL-C (by about $37.9,58.9$ and $142.9 \%$; respectively), while showed significant lower level of HDL-C (by about 29.7\%) compared to control rats, Table (3). The treatment of NAFL rats with Pomegranate peel extract result in significantly dose-dependent decline in the level of $\mathrm{TG}$ and $\mathrm{TC}$ compared to the untreated rats, Table (3). On the other hand the level of HDL-C showed dose-dependent increase in the NAFL rats treated with Pomegranate peel extract, Table (3). 
Table 3. Lipid parameter

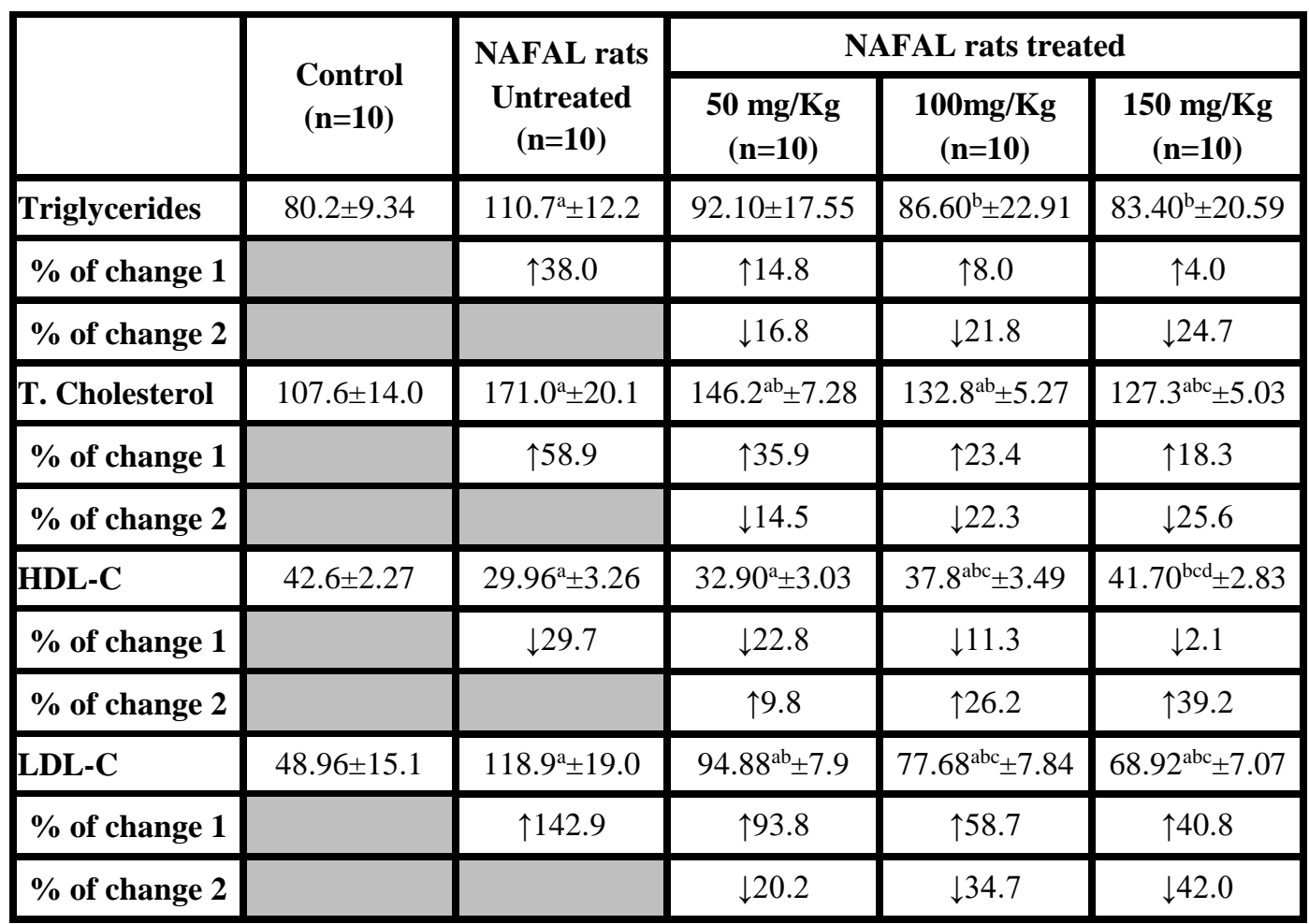

Data was expressed as mean \pm SD.

a: significant with Control group at $p \leq 0.05$

b: significant with Untreated group at $p \leq 0.05$

c: significant with $\mathbf{5 0} \mathbf{~ m g / K g}$ treatedgroup at $\mathrm{p} \leq 0.05$

$\mathrm{d}$ : significant with $\mathbf{1 0 0} \mathbf{~} \mathbf{m g} / \mathbf{K g}$ treatedgroup at $\mathrm{p} \leq 0.05$

$\%$ of change 1: from Control group

$\%$ of change 2: from Untreated group

\subsubsection{Hepatic lipid contents:}

Table 4. Hepatic lipid contents

\begin{tabular}{|c|c|c|c|c|c|}
\hline \multirow[b]{2}{*}{ Hepatic } & \multirow{2}{*}{$\begin{array}{c}\text { Control } \\
(n=10)\end{array}$} & \multirow{2}{*}{$\begin{array}{c}\text { NAFAL rats } \\
\text { Untreated } \\
(\mathbf{n}=10)\end{array}$} & \multicolumn{3}{|c|}{ NAFAL rats treated } \\
\hline & & & $\begin{array}{c}50 \mathrm{mg} / \mathrm{Kg} \\
(\mathrm{n}=10)\end{array}$ & $\begin{array}{c}100 \mathrm{mg} / \mathrm{Kg} \\
(\mathrm{n}=10)\end{array}$ & $\begin{array}{c}150 \mathrm{mg} / \mathrm{Kg} \\
(\mathrm{n}=10)\end{array}$ \\
\hline Cholesterol & $24.80 \pm 4.59$ & $87.35^{\mathrm{a}} \pm 9.43$ & $50.90^{\mathrm{ab}} \pm 19.13$ & $33.10^{\mathrm{bc}} \pm 12.27$ & $25.90^{\mathrm{bc}} \pm 13.35$ \\
\hline$\%$ of change 1 & & $\uparrow 252.2$ & $\uparrow 105.2$ & $\uparrow 33.5$ & $\uparrow 4.4$ \\
\hline$\%$ of change 2 & & & $\downarrow 41.7$ & $\downarrow 62.1$ & $\downarrow 70.3$ \\
\hline Triglycerides & $33.40 \pm 10.80$ & $128.0^{\mathrm{a}} \pm 15.64$ & $71.20^{\mathrm{ab}} \pm 19.10$ & $52.20^{\mathrm{abc}} \pm 3.36$ & $37.90^{\mathrm{bc}} \pm 8.91$ \\
\hline$\%$ of change 1 & & $\uparrow 283.2$ & $\uparrow 113.2$ & $\uparrow 56.3$ & $\uparrow 13.5$ \\
\hline$\%$ of change 2 & & & $\downarrow 44.4$ & $\downarrow 59.2$ & $\downarrow 70.4$ \\
\hline
\end{tabular}

The hepatic tissues of untreated NAFL rats have greatly elevated contents of triglycerides (by about $283.2 \%$ ) and cholesterol (by about $252.2 \%$ ) compared to the hepatic tissues of control rats Table (4).The NAFL rats treated with pomegranate peel extract showed significant down regulation of hepatic contents of triglycerides and cholesterol in a dose-dependent manner, Table (4). 
Data was expressed as mean \pm SD.

a: significant with Control group at $p \leq 0.05$

b: significant with Untreated group at $p \leq 0.05$

c: significant with $\mathbf{5 0} \mathbf{~ m g / K g}$ treatedgroup at $\mathrm{p} \leq 0.05$

$\%$ of change 1: from Control group

$\%$ of change 2: from Untreated group

\subsection{Hepatic expression of MicroRNA- 33a and MicroRNA-34a:}

The hepatic level miR-34a was greatly increased in the untreated NAFL rats by about $909.7 \%$ compared to control rats,(figure 1). The NAFL rats treated with pomegranate peel extract showed a dose-dependent reduction of $\mathrm{miR}-34 \mathrm{a}$ compared to the untreated rats.

The hepatic level miR-33a was decreased in the untreated NAFL rats by about 42.4\% compared to control rats, (figure 1). The NAFL rats treated with pomegranate peel extract showed a dosedependent elevation of miR-33a compared to the untreated rats (figure 1).

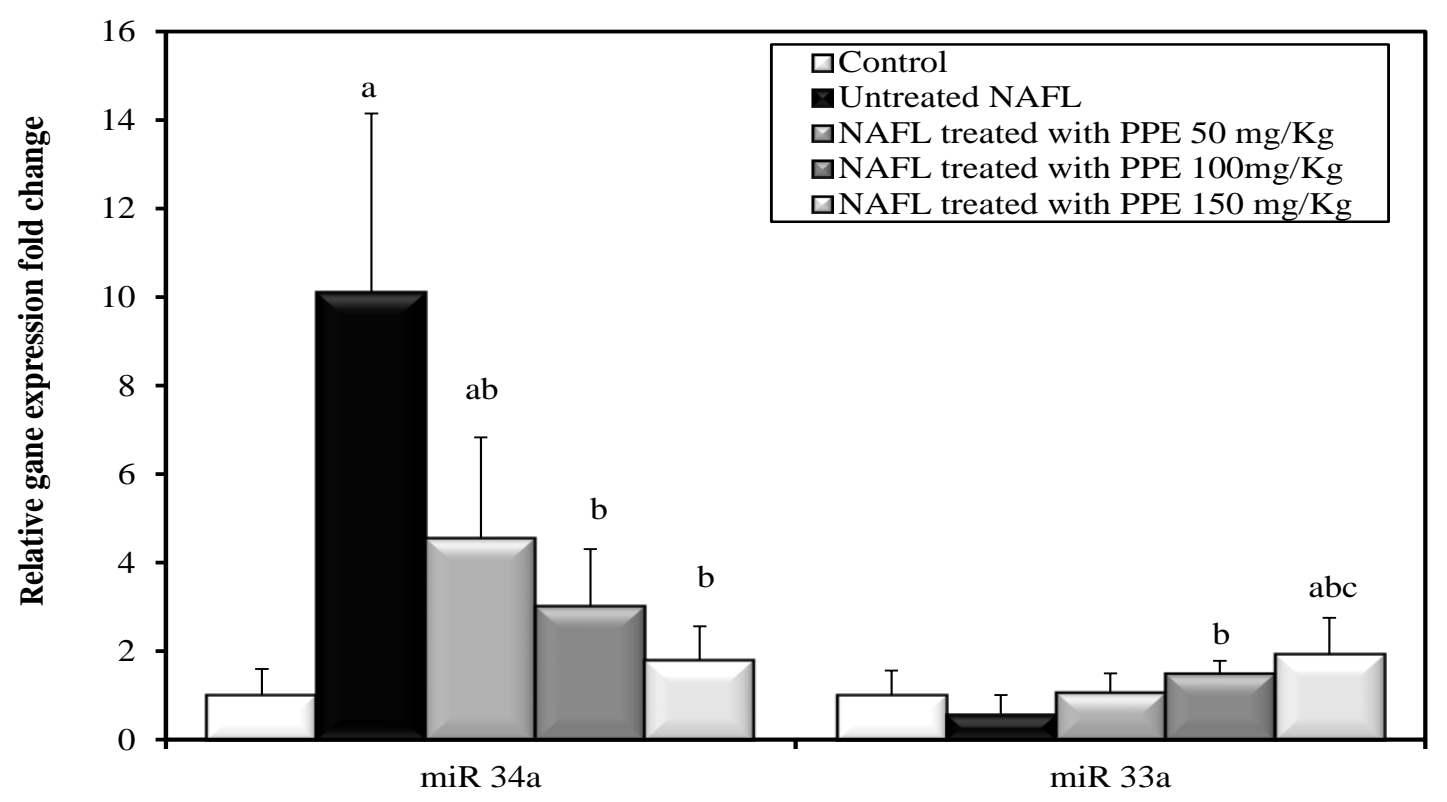

Fig. 1. MicroRNA-33a and MicroRNA-34a

a: significant with Control group at $\mathrm{p} \leq 0.05$

b: significant with Untreated group at $\mathrm{p} \leq 0.05$

c: significant with $\mathbf{5 0} \mathbf{~ m g / K g}$ treatedgroup at $\mathrm{p} \leq$ 0.05

\section{DISCUSSION:}

In the present study, feeding male Wistar rats HFD for 14 weeks resulted in manifestations of fatty liver with signs of steatohepatitis. In accordance with our results,using the same type of high-fat diet in rats (Lieber $\boldsymbol{e t}$ al., 2004) and mice (Van Rooyen et al., 2011), produced similar hepatic lesions of human NASH. These histological changes in hepatic tissue were associated with significant alterations in many biochemical pathways that may be involved in the pathogenesis of the NAFL or may be consequences of the disease condition.

NAFL rats demonstrated significant hepatic accumulation of triglycerides and cholesterol which were higher by about 283.2 and $252.2 \%$ respectively compared to control values. Also, the activities of serum transaminases; AST, ALT and GGT were significantly elevated by about $53.1 \%, 95.2 \%$ and $292.6 \%$; respectively 
compared to control rats. Also, NAFL rats showed higher bilirubin value by about $252.8 \%$. These abnormalities of liver function tests indicated significant hepatocytes inflammation, damage and necrosis.

At the glucose homeostasis level, NAFL rats showed a significant elevation in fasting blood glucose, insulin and HOMA-insulin resistance index (by about 74.2, 118.8 and 274.1\%, respectively) that indicated a state of insulin resistance which is considered as the first hit for hepatic fat accumulation and steatosis. The increase in fasting plasma glucose concentration is due to the impaired ability of insulin to inhibit hepatic glucose production (by glycogenolysis and gluconeogenesis) (Ryysy L et al., 2000).

In the present study, NAFL rats demonstrated significant hepatic accumulation of lipids where the hepatic contents of triglycerides and cholesterol were increased. The results of lipid content of the liver of NAFL rats showed significantly higher level.

The present study indicated that the metabolic abnormalities in NAFL rats are associated with deranged hepatic expression of microRNAs as indicated by significant suppression of miR-33a by about half-control value and significant induction of miR-34a expression by about 9-fold control value.

The Pomegranate considered one of the most important plants used in alternative medicine because it contains phenolic and flavonoid substances are very important plant constituents because of their antioxidant activity

(Abdel Moneim, 2012).

The present study was undertaken to evaluate the anti-steatotic effects of pomegranate peel extract (PPE) and to explore microRNAs (miR-33a and miR34a) as a molecular target of its effect.

The present study documents the ameliorating effects of PPE on hyperglycemia, insulin resistance and liver functions in NAFL rats in a dosedependent manner compared to untreated rats. The results clearly indicated the strong glucose-lowering effect of PPE as it significantly corrects the fasting blood glucose, insulin and normalizes insulin sensitivity that may mean PPE enhance insulin sensitivity in peripheral tissues which manifested as decreased HOMAIRI. PPE may thus have a potential clinical utility in combating NAFLD. The exact molecular mechanism involved in the influence of PPE on glucose and lipid homeostasis is unclear, so in this study, the probable involvement of miR-33a and miR-34a in this mechanism was explored.

The results of the present study showed that there were significant decreases in serum activities of AST, ALT and GGT in NAFL rats treated with PPE in a dosedependent manner. This effect is due to antioxidant content of pomegranate peel. Also, treatment by PPE completely normalizes the level of serum bilirubin.

The PPE supplementation causes a significant dose-dependent decline in the hepatic expression of miR-34a while significantly enhance the hepatic expression of miR-33a in a dosedependent manner. The modulating 
effects of PPE on gene expression are in line with the previous study of Taha et al. 2016, who reported significant downregulation of the gene expression of SREBP-1c, SREBP-2, fatty acid synthase (FAS) and 3-hydroxy-3-methylglutarylCoA reductase (HMGCR) upon PPE treatment in HepG2 cell line (Taha et al., 2016).

The correlation pattern obtained in the present study may suggested that, the therapeutic effects of PPE may be mediated through down-regulation of miR-34a and up-regulating miR-33a; as hepatic miR-34a in treated rats is positively correlated with the activity of the liver function parameters (ALT, AST, and bilirubin), glucose homeostasis parameters (FBS and HOMA), and lipid profile (serum $\mathrm{TG}$, serum $\mathrm{TC}(\mathrm{r}=0.659)$, LDL-C, hepatic cholesterol and hepatic TG) and negatively correlated with serum HDL-C. On the other hand miR-33a showed opposite pattern of correlation.

The suggested role of miR-34a and miR$33 \mathrm{a}$ in mediating the anti-steatotic effect of PPE may be supported by the study of Ding et al., 2015 who showed that silencing miR-34a led to an initially increased expression of PPAR $\alpha$, SIRT1 and PPAR $\alpha$ 's downstream genes and activation of the AMP-dependent kinase (AMPK) the central metabolic sensor. The miR-34a inhibitor suppressed lipid accumulation and improved the degree of steatosis.

Taken together, our data indicated the anti-steatotic effects of PPE in HFDinduced NAFLD in rats and these effects may be mediated through modulation of hepatic expression of expression of miR- 34a and miR-33a which potentially contribute to altered lipid and glucose metabolism in NAFLD.

\section{CONCLUSION}

From the results of the present study we can conclude thatNAFLD is easy to be established by high-fat diet and In NAFLD state the liver function (SGPT, SGOT, GGT and bilirubin) and glucose hemostasis (HOMA-IR, insulin and FBG) are increased. Treatment by PPE reduces accumulation of fat in the liver and decline the hepatic lipid content and serum TG, TC, and LDL-cholesterol. Treatment by PPE improves liver enzymes. From this study we observed that there is a relation between MiR-34a and MiR-33a expression with NAFLD and its expression changed by treatment of PPE.

Recommended, the medical company to apply this research on human to using PPE as medical drug for treatment of NAFLD.

\section{References:}

Abdel, Moneim, A. E. (2012). Antioxidant activities of Punicagranatum (pomegranate) peel extract on brain of rats. Journal of Medicinal Plants Research; vol. 6(2): 195-9.

Budhu, A.; Jia, HL.\&Forgues M, et al. (2008). Identification of metastasisrelated microRNAs in hepatocellular carcinoma. Hepatology; 47:897-907.

Burtis, C.; Ashwood, ER.\&Bruns, DE. (2006). Tietz Textbook of Clinical 
Chemistry and Molecular

Diagnostics. $4^{\text {th }}$ Ed. Elsevier

Saunders Company, St Louis; pp. 1788-98.

Cam , M.; Hisil, Y. \&Durmaz, G. (2009)

Classification of eight pomegranate juices based on antioxidant capacity measured by four methods. Food Chemistry, vol. 112(3):721-6.

Celik, I.; Temur, A. \&Isik, I. (2009).Hepatoprotective role and antioxidant capacity of pomegranate (Punicagranatum) flowers infusion against trichloroacetic acid-exposed rats, Food and Chemical Toxicology. vol. 47(1):145-9.

Cermelli, S.; Ruggieri, A.; Marrero, JA.;Ioannou, GN.\& Beretta, L. (2011). Circulating microRNAs in patients with chronic hepatitis $\mathrm{C}$ and non-alcoholic fatty liver disease. PLoS One; 6, e23937.

Davidson, M. H.; Maki, K. C.; Dicklin, M. R.; Feinstein, S. B.; Witchger, M. S.; Bell, M.; McGuire, D. K.; Provos, J. C.; Liker, H. \&Aviram, M. (2009). Effects of consumption of pomegranate juice on carotid intima-media thickness in men and women at moderate risk for coronary heart disease. The American Journal of Cardiology, vol. 104(7):936- 42.

Ding, Jiexia; Meng, Li.; Xingyong, Wan.; Xi, Jin.; Shaohua, Chen; Chaohui, Yu.\&Youming, Li. (2015).
Effect of miR-34a in regulating steatosis by targeting PPAR $\alpha$ expression in nonalcoholic fatty liver disease. Scientific RepoRts; 5:13729.

Feng, X-T.; Tang, S-Y.; Jiang, YX.\&Zhao, W. (2017). AntiDiabetic Effects of Zhuoduqing Formula, a Chinese Herbal Decoction, on a Rat Model of Type 2 Diabetes. African J Tradit Complement Altern Med.; 14(3):42-50.

Folich, J.; Lees, M.\& Sloane, Stanley, GH. (1957). A simple method for the isolation and purification of total lipids from animal tissues. The Journal of Biological Chemistry; 226:497-509.

Friedewald, WT.; Levy, RI.\&Fredrickson, DS. (1972). Estimation of the concentration of low-density lipoprotein cholesterol in plasma, without use of the preparative ultracentrifuge. Clin Chem.; 18(6):499-502.

Hamad, A. W. \& Al-Momene, W. (2009). Separation and purification of crude Ellagic acid from white flesh of pomegranate fruits as a potent anti-carcinogenic. New Biotechnology, vol. 25(1):286.

Hossin, F. L. (2009). Effect of Pomegranate (Punicagranatum) Peels and It's Extract on Obese Hypercholesterolemic Rats. Pakistan Journal of Nutrition, vol. 8 (8):1251-7. 
Kirkpatrick, LA.; Feeney, BC. (2013). A simple guide to IBM SPSS statistics for version 20.0. Student ed. Belmont, Calif.: Wadsworth, Cengage Learning.

Kotz, S.; Balakrishnan, N.; Read, CB.\&Vidakovic, B. (2006). Encyclopedia of statistical sciences. 2nd ed. Hoboken, N.J.: Wiley-Interscience.

Lapornik, B.; Prosek, M. \&Wondra, AG. (2005). Comparison of extracts prepared from plant by products using different solvents and extraction time. J Food Eng.; 71:214-22.

Lieber, CS.; Leo, MA.;Mak, KM.; Xu, Y.; Cao, Q. \&Ren, C, et al. (2004). Model of non-alcoholic steatohepatitis. Am J ClinNutr.; 79(3):502-9.

Pais, R.; Charlotte, F.; Fedchuk, L.; Bedossa, P.; Lebray, P. \&Poynard, $\mathrm{T}$, et al. (2013). A systematic review of follow-up biopsies reveals disease progression in patients with non-alcoholic fatty liver. J hepatology; 59(3):550-6.

Pastori, D.; Polimeni, L.; Baratta, F.; Pani, A.; Del Ben, M. \& Angelico, F. (2015). The efficacy and safety of statins for the treatment of nonalcoholic fatty liver disease. Dig Liver Dis.; 47(1):4-11.

Rayner, K. J.; Esau, C. C. \&Hussain, F. N. et al. (2011). "Inhibition of miR$33 \mathrm{a} / \mathrm{b}$ in non-human primates raises plasma HDL and lowers VLDL triglycerides. Nature; 478:404-407.
Rifai, N. \&Warnick, GR. (2008). Lipids, Lipoproteins, Apolipoproteins, and Other Cardiovascular Risk Factors. In: Burtis CA, Ashwood ER and, Bruns DE, editors. Tietz Text Book of Clinical Chemistry and Molecular Diagnostics. 6th Ed. Elsevier Saunders Company, St Louis, p. 402-30.

Ryysy, L.; Häkkinen, A-M.; Goto, T.; Vehkavaara, S.; Westerbacka, J. \&Halavaara, J. et al. (2000). Hepatic fat content and insulin action on free fatty acids and glucose metabolism rather than insulin absorption are associated with insulin requirements during insulin therapy in type 2 diabetic patients. Diabetes; 49(5):749-58.

Sene-Fiorese, M.; Duarte, F. O.; Scarmagnani, F. R.; Cheik, N. C.; Manzoni, M. S.; Nonaka, K. O.; Rossi, E.A.; de Oliveira Duarte, A.C. \&Dâmaso, A. R. (2008). Efficiency of intermittent exercise on adiposity and fatty liver in rats fed with high-fat diet. Obesity; 16(10), 2217-2222.

Singh, M.; Arseneault, M.; Sanderson, T.; Morthy, V. \&Ramassamy, C. (2008). Challenges for research on polyphenols from foods in Alzheimer's disease: bioavailability, metabolism and cellular and molecular mechanism. Journal of Agricultural and Food Chemistry, vol. 56(13):4855-73.

Souza, MR.; DinizMde, F.; MedeirosFilho, JE.\&Araújo, MS. (2012). Metabolic syndrome and risk 
factors for non-alcoholic fatty liver disease. ArqGastroenterol.; 49 (1):89-96.

Svegliati-Baroni, G.; Candelaresi, C.; Saccomanno, S.; Ferretti, G.; Bachetti, T. \&Marzioni, $M$ et al. (2006). A model of insulin resistance and non-alcoholic steatohepatitis in rats which ameliorated the degree of liver injury. Am J Pathol, 169:846-60.

Taha, OA.;Barakat, A.; Abdelhakim, HA.; Shemis, MA. \&Zakaria, Z. (2016).Hypolipidemic and antifatty liver effects exerted by standardized punicagranatum 1 . peel extract in hepg2 cell-line and high-fat diet-induced mice. Int $\mathrm{J}$ Pharm PharmSci, 6, 156-161.

Van der Meer, AJ.; Veldt, BJ. \& Feld JJ, et al. (2012). Association between sustained virological response and all-cause mortality among patients with chronic hepatitis $\mathrm{C}$ and advanced hepatic fibrosis. JAMA; 308:2584-93.

Van Rooyen, DM.; Larter, CZ.; Haigh, WG.; Yeh, MM.; Ioannou, G. \&Kuver, R. et al. (2011). Hepatic free cholesterol accumulates in obese, diabetic mice and causes non-alcoholic steatohepatitis. Gastroenterology; 141: 1393-403.

Younossi, ZM.; Diehl, AM. \&Ong, JP. (2002). Non-alcoholic fatty liver disease: an agenda for clinical research. Hepatology; 35:746-52.

Zhen, He.; Cheng, Hu. \&Weiping, Jia. (2016). MiRNAs in non-alcoholic fatty liver disease. Front. Med, 10(4): 389-396. 